\title{
Correction of facial asymmetry using a patient-specific three-dimensional printed polycarprolactone/beta tricalcium phosphate scaffold: a case report
}

\author{
Min-Keun Kim ${ }^{1 *}$, Jin-Woo Han², Kwang-Jun Kwon' ${ }^{1}$, Young-Wook Park ${ }^{1}$, and Jin-Hyung Shim ${ }^{3 *}$ \\ ${ }^{1}$ Professor, Department of Oral and Maxillofacial Surgery, College of Dentistry, Gangneung-Wonju National University, Gangneung, Republic of Korea \\ ${ }^{2}$ Professor, Department of Oral and Maxillofacial Radiology, College of Dentistry, Gangneung-Wonju National University, Gangneung, Republic of Korea \\ ${ }^{3}$ Researcher, Research Institute, T\&R Biofab Co., Ltd., Siheung, Republic of Korea
}

Facial asymmetry is difficult to correct mainly because of the large volume of implant required for reconstruction, which is hard to estimate. Computer-aided surgical planning using three-dimensional (3D)-printed implants is developing rapidly, with promising clinical results being reported in reconstructive, orthognathic, and other surgical fields. A 54-year-old male patient presented with facial asymmetry caused by fibular free flap displacement. This was surgically corrected using a customized, 3D-printed polycarprolactone/ beta tricalcium phosphate scaffold. The implant fit well and was easily fixed to the right mandibular angle area, resulting in an improvement in the facial contour of the patient. Throughout the follow-up period, the PCL/ $\beta$-TCP implant was detected using an ultrasonic device and remained without volumetric change. There was also no wound dehiscence or implant displacement. Thus, a patient-specific 3D-printed biodegradable scaffold can effectively facilitate surgical correction of facial asymmetry. However, facial contour sequelae, stability, and resorption must be assessed over a long-term follow-up period.

Key Words: Betatricalcium phosphate; Facial asymmetry; Polycarprolactone; Printing; Three dimensional

(c) This is an open-access article distributed under the terms of the Creative Commons Attribution Non-Commercial License (http://creativecommons.org/licenses/by-nc/4.0) which permits unrestricted noncommercial use, distribution, and reproduction in any medium, provided the original work is properly cited.

\section{Introduction}

Facial asymmetry often develops after reconstructive surgery using a vascularized free flap [1]. This kind of asymmetry is difficult to correct because large volumes of graft materials or implants are required. Furthermore, it is very difficult to estimate the amount of materials that are required for such reconstruction. So far, computer-aided surgical planning, surgical guiding, and three dimensional
(3D)-printed implant surgery are developing rapidly [2] These technologies have produced good clinical results in reconstructive, orthognathic, and other surgical fields [3-7]. Computer-aided surgical planning allows a patient-specific implant to be designed and fabricated with great accuracy prior to surgery. Further, it allows the surgical objective to be determined preoperatively. This helps to reduce the operating time and improves surgical results [8].

Polycaprolactone (PCL) is a biocompatible and biode-

Received July 12, 2021; Accepted July 19, 2021

*Co-Corresponding author: Min-Keun Kim, Department of Oral and Maxillofacial Surgery, College of Dentistry, Gangneung-Wonju National University, 7, Jukheon-gil, Gangneung 25457, Republic of Korea.

Tel: +82-33-640-2753, Fax: +82-33-640-2753, E-mail: omfsmk@gwnu.ac.kr

${ }^{\star}$ Co-Corresponding author: Jin-Hyung Shim, Research Institute, T\&R Biofab Co., Ltd., 237 Sangidaehak-ro, Siheung 15073, Republic of Korea. Tel: +82-31-431-3344, Fax: +82-31-8041-1783, E-mail: happyshim@tnrbiofab.com 
gradable synthetic polymer that has excellent mechanical strength and durability compared to other synthetic polymers, such as polylactic acid and lactic-co-glycolic acid. PCL is a biodegradable material that slowly degrades over a period of 2-4 years, depending on its molecular weight and crystallinity. Further, PCL has rheological and viscoelastic properties that are superior to those other synthetic polymers, therefore, it can be easily used to fabricate implants and medical devices. PCL is a US Food and Drug Administration (FDA)-approved biomaterial [9]. Many researchers and surgeons have continued to use PCL in bone transplant surgery $[10,11]$. Beta-tricalcium phosphate [Ca3(PO4)2] ceramics are biocompatible and osteoconductive materials that contain minerals (i.e., $\mathrm{Ca}^{2+}$ and $\mathrm{PO}_{4}^{3-}$ ) that are naturally found in bone [12]. South Korean researchers and surgeons have reported the effect of Polycarprolactone/beta tricalcium phosphate (PCL/ $\beta$-TCP) scaffold on mandibular reconstruction in canine models [13]. The purpose of this article was to describe the use of a patientspecific 3D-printed PCL/ $\beta$-TCP implant and to evaluate the effect of this implant on the surgical correction of facial asymmetry.

\section{Case description}

\section{Patient's history}

A 54-year-old male patient presented with facial asymmetry due to displacement of a free vascularized fibular flap that performed in January 2015. This patient was diagnosed ameloblatoma and partial mandibulectomy and fibular free flap reconstruction was performed. Displacement of the fibular flap occurred gradually, parallel to loosening of a 2.0 mm miniplate (M3) screw. In January 2016, a dental implant was placed. However, infection and pathologic fracture of the fibular flap occurred in November 2017. Further, saucerization was performed, and an anterior iliac bone graft was performed on the fibular flap on February 9, 2018. A patient specific implant was inserted on October 17, 2019 (Fig. 1). Written informed consent was obtained from the patient.

\section{D customized implant fabrications}

A patient-specific implant (BellaPore PSI Plus; T\&R Biofab Co., Ltd., Siheung, Korea) containing biodegradable materials (PCL/ $\beta$-TCP, 8:2) was fabricated using $3 \mathrm{D}$-printing. The process was performed at a kMFDS-accredited facility that had received Good Manufacturing Practice certifica-
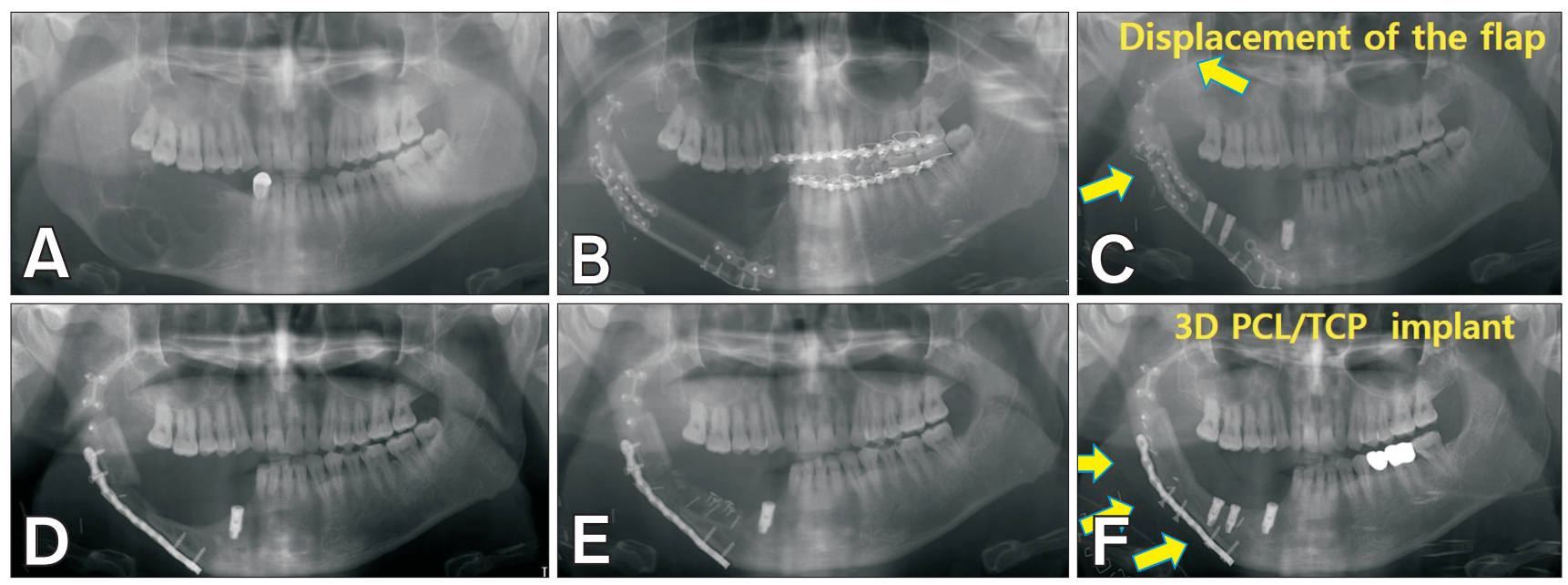

Fig. 1. Patient's history. (A) Initial visit of the patient (Dec 26, 2014). (B) Partial mandibulectomy and fibular reconstruction (Jan 9, 2015). (C) Displacement of the fibular flap (Jan 21, 2016). Arrow indicate displacement of the fibular flap. (D) Osteomyelitis and pathologic fractures of the fibular flap (Nov 13, 2017). (E) Iliac bone graft (Feb 9, 2018). (F) Patient specific 3D PCL/TCP implant (Oct 17, 2019). Arrow indicate the patient specific 3D PCL/TCP implant. 3D, three dimensional; PCL, polycaprolactone; TCP, tricalcium phosphate. 
tion (T\&R Biofab Co., Ltd.). The customized implant was designed with completely interconnected 3D pores that were a result of the characteristics of the 3D printing-based fabrication method. In the case in this report, the scaffolds were fabricated with a reference pore size of 400-600 $\mu \mathrm{m}$, which was expected to promote maximal tissue in-growth. Since we did not use seed cells in combination with the implantation of the scaffold, the in-growth of cells within the scaffold only had the potential to occur as a result of the integration of native tissue within the scaffold. In this patient, the position of the fibular flap was stable, and we planned reconstructive surgery to improve facial esthetics (Fig. 2).

\section{Surgical procedures}

The submandibular approach was used to reach the defect. Afterward, we performed a wide dissection for implant insertion and tension-free suturing. After the reconstruction plate was exposed substantially, we adapted the PCL/ $\beta$-TCP implant with some modification to fit the surgical field (Fig. 3). After removing the mini screws, the implant was fixed using both the removed mini screws and new micro screws (Fig. 4). Botulinum toxin type A (Meditox, Cheongwon, Korea) was injected into both masseter muscles (25 units for each side) to reduce the muscular force on the PCL/ $\beta$-TCP implant.

\section{Surgical outcome}

The clinical results of the surgery are shown in Fig. 5. Facial asymmetry improved, and no signs of acute step or compression of facial appearance or displacement of the PCL $/ \beta$-TCP implant were observed. The patient-specific implant fitted well and was easy to modified to fit the defect throughout the surgery (Fig. 3, 4)

After a 20-month follow-up period, the patient felt better and was satisfied with the facial esthetics that resulted from the surgery (Fig. 5). Further, no foreign body reaction, wound dehiscence, or implant movement was observed.

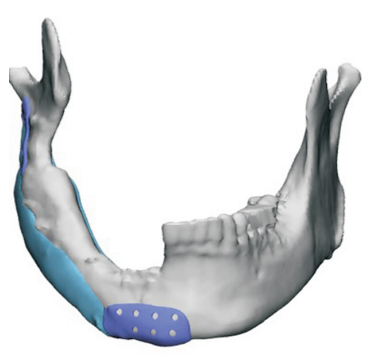

Front view

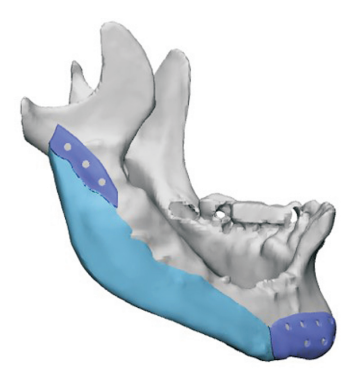

Right view

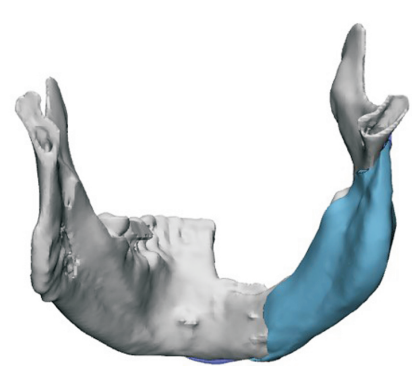

Rear view
Fig. 2. Three-dimensional digital modeling from patient's computed tomographic data.

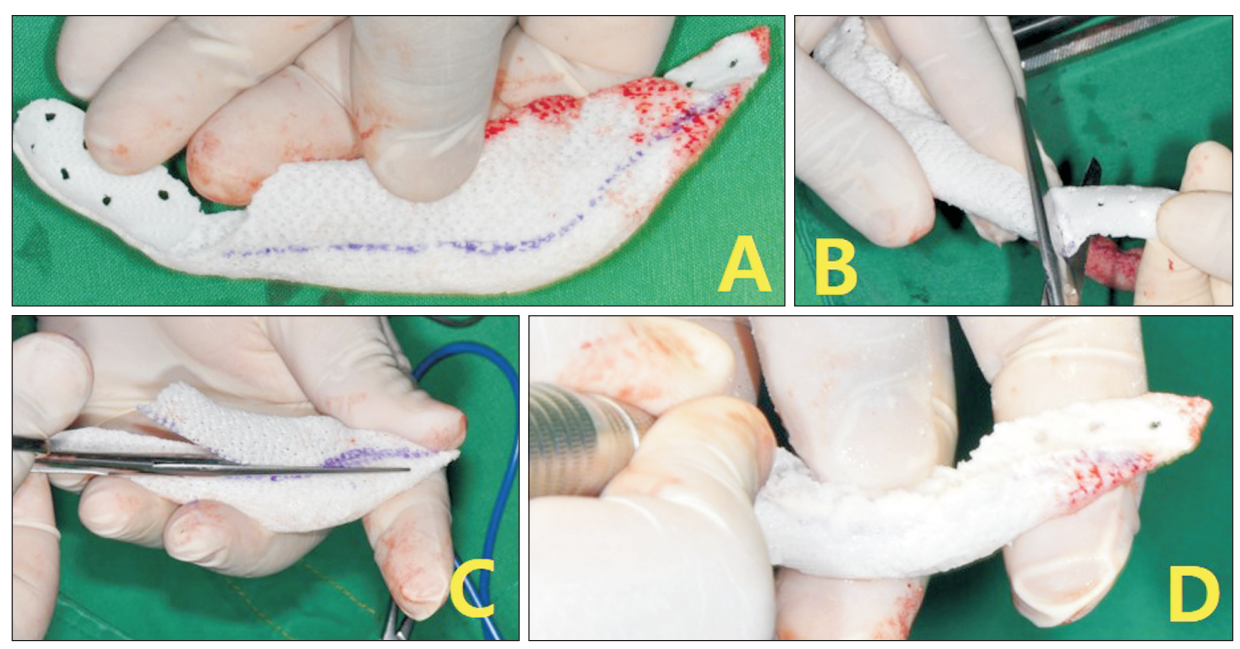

Fig. 3. Modification of the printed implant intraoperatively. (A) Marking the excess using the marking pencil. (B) Reducing the anterior excess using the scissor. (C) Reducing the lingual margins using the scissor. (D) Margin smoothening using the electronic burs. 

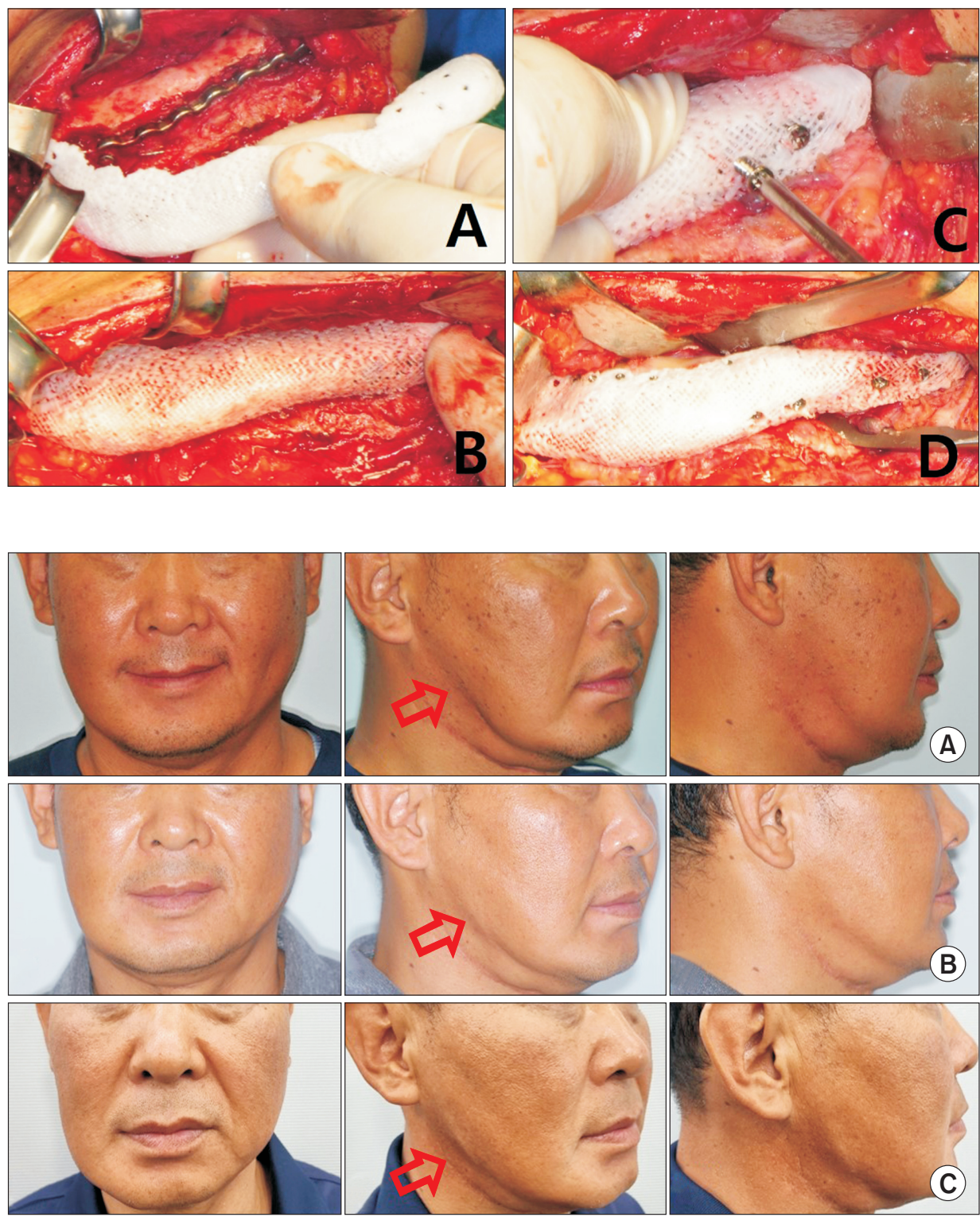

(B)
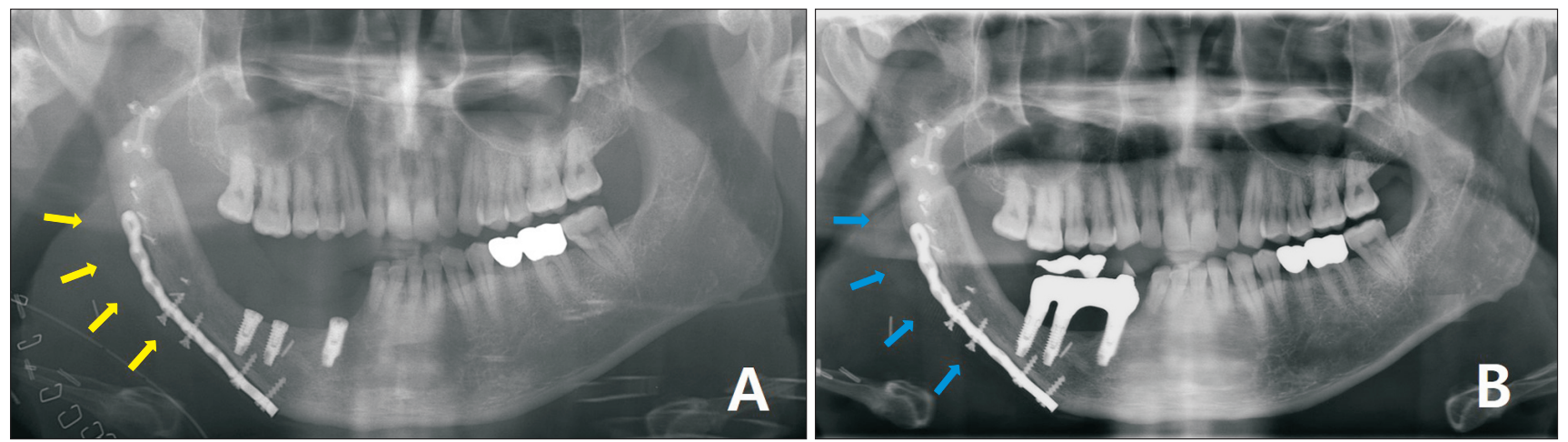

Fig. 6. Radiographic follow-up. (A) Postoperative 1 days. (B) Postoperative 20 months. Arrow indicate the porfile of the patient specific 3D PCL/ TCP implant.
Fig. 4. Adaptation and fixation of the printed implant. (A) Initial adaptation trial of the implant. (B) Finial position of the printed implant after implant modification. (C) Mini screw fixation on R-late hole. (D) Final fixation using 4 mini screws on R-plate hole and 5 micro screws on lateral upper borders of the implant.

Fig. 5. Clinical appearances of the patient. (A) Pre-operative status. (B) Post-operative 12 months. (C) Postoperative 20 months. Arrow indicate improved facial profile. 

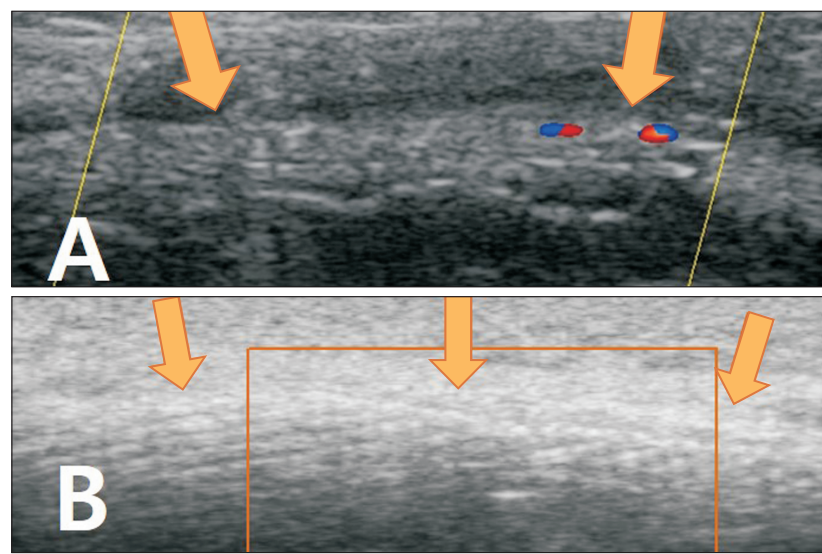

Fig. 7. Ultrasonographic follow up (Alpinion E-CUBE 9; Alpinion, Seoul, Korea). (A) Postoperative 2 weeks. (B) Postoperative 1 year. Arrow indicate the 3D PCL/TCP implant.

Ultrasonographic and radiographic follow-up revealed that the positon of the implant was stable with minimal volumetric changes during the 20-month follow-up period (Fig. 6, 7). The implant was observed using ultrasonography, which was particularly useful in monitoring the volumetric stability of the implant and its rate of degradation.

\section{Discussion}

In the case described herein, facial asymmetry caused by the displacement of a free vascularized fibular flap was corrected using a patient-specific 3D-printed PCL/ $\beta$-TCP (8:2) implant and maintained for 20 months without any kind of complications, such as wound dehiscence, implant extrusion, or foreign body reactions. One of the factors that led to the displacement of the free flap was the masticatory muscular forces of the masseter, pterygoid, and temporalis muscles. Hence, the reconstructive surgeon should consider not only strong fixation but also reducing the muscular force using botulinum toxin type A injections when planning mandibular reconstructive surgery [14,15].

PCL is a biocompatible biomaterial approved by the FDA in the USA and is used in various fields as a biomaterial. It has good solubility, has a low melting point (59\%-64\%), and is easy to blend with other biomaterials. Thus, PCL is applied in various biomedical areas, such as drug-delivery systems, medical devices, and tissue engineering [16]. In an in vivo study involving rats, PCL degradation started from the second year [17]. In this report, the first step is to decrease molecular weight using hydrolytic degradation without deformation the PCL 2 years after implantation. In the second step, PCL loses strength gradually and breaks into pieces (less than 3,000 $\mu \mathrm{m}$ ). Tricalcium phosphate (TCP) is a bone component and is used widely as a bone substitute due to its osteoconductivity, biocompatibilities, and long shelf life. TCP can also preserve structural stability by releasing a large amount of calcium and sulfate ions and indispensable inorganic salts for new bone formation [18]. To improve the osteoconductivities and mechanical properties, the PCL/ $\beta$-TCP complex is developed. In an in vivo study on this PCL $/ \beta$-TCP complex implant, PCL/ $\beta$-TCP implant was applied within the mandibular defect in a rabbit model and it showed better osteogenic effects than those of the PCL-only group. In this experiment, PCL/ $\beta$-TCP scaffolds showed good mechanical stabilities and did not lead to no other complications [13].

Various clinical applications of 3D-printed PCL implant have been reported in the management of cleft alveoli, augmentation rhinoplasty, nasal septal deformity, orbital wall reconstruction, and complex maxillary defect [11,1923]. In the case of a cleft alveolus, the PCL scaffold with human bone marrow cells was found to have a newly regenerated bone volume that was approximately $45 \%$ of the total defect volume at 6 months after implantation [11]. A study showed that in augmentation rhinoplasty, among 101 patients, 98.0\% had no foreign body reactions and maintained efficacy during the 18-month follow-up period. Histologic analysis showed tissue infiltration into the pores of the PCL mesh, and neo-cartilage tissues and collagen around the mesh were observed [19]. In cases of nasal septal deformities, a multicenter clinical trial of 20 patients with septal deviations that were managed using 3D-printed PCL implant, it was found that PCL implant provided proper mechanical support and had excellent biocompatibility and surgical manipulability [20]. In an inferomedial orbit implant, five implants showed no extrusions and structural stabilities during the mean follow-up period of 20.8 (18-27) months [21]. In the cases of three complex maxillary defects, the PCL scaffold was stable in the maxillary defect and promoted regeneration of the deficient tissues in 2 years [22]. In these clinical trials, the PCL scaffolds showed 
stable biocompatibility and structural stability.

In this case report, we used a patient-specific 3D-printed PCL/ $\beta$-TCP complex (8:2) applied to the mandibular inferior border and the posterior border with a large volume that corresponded to the area that is compressed by the masseter muscles and pterygomasseteric sling. The position of the implant was found to be stabile after 20 months, and it also showed volumetric stability. We manipulated this blended scaffold that had micropore, which were 400-600 $\mu \mathrm{m}$ in size, to facilitate living tissue ingrowth within this space during the observation period. As the TCP might have had some osteoconductive effect with the contact area with the mandible, it improved the long-term stability of the implant. This case is unique because the implant was used in the mandibular border, around the area acted upon by the masticatory muscles. We injected botulinum toxin type A within the masseter muscles bilaterally to reduce the muscular force, which can decrease the pressure to the implant and prevent its displacement. The material used is also detectable using an ultrasonographic device, which was useful for monitoring implant volume and displacement and degradation. Advantages of a PCL $/ \beta$-TCP implant include its elasticity and softness. In the operating room, an implant may need to be modified to improve its fit and stability. Further, the fixation of PCL/ $\beta$-TCP implants is easy using micro- and mini-screws.

In conclusion patient-specific 3D PCL/TCP scaffolds were applied in the mandibular angle and lower and posterior border and showed good volumetric stability after 20 months. This implant is easy to modify intraoperatively and it is easy to make fixations. Available ultrasonographic and radiographic follow-up data should be followed-up to confirm the long-term stability of this blended customized implant.

\section{Acknowledgements}

This study was supported by 2018 Academic Research Support Program in Gangneung-Wonju National University. This study was supported by the National Research Foundation of Korea (NRF) grant funded by the Korea government (MSIT) (No.:2018R1C1B5086579).

\section{Conflicts of Interest}

The authors declare that they have no competing interests.

\section{ORCID}

\author{
Min-Keun Kim \\ https://orcid.org/0000-0002-5481-841X \\ Jin-Woo Han \\ https://orcid.org/0000-0002-8604-7330 \\ Kwang-Jun Kwon \\ https://orcid.org/0000-0003-1552-3974 \\ Young-Wook Park \\ https://orcid.org/0000-0001-5881-7257 \\ Jin-Hyung Shim \\ https://orcid.org/0000-0002-5407-9020
}

\section{References}

1. Kang SH, Lee S, Nam W. Condyle dislocation following mandibular reconstruction using a fibula free flap: complication cases. Maxillofac Plast Reconstr Surg 2019;41:14. doi: 10.1186/s40902-019-0197-1.

2. Oh JH. Recent advances in the reconstruction of craniomaxillofacial defects using computer-aided design/computer-aided manufacturing. Maxillofac Plast Reconstr Surg 2018;40:2. doi: 10.1186/s40902-018-0141-9.

3. Lee WB, Choi WH, Lee HG, Choi NR, Hwang DS, Kim UK. Mandibular reconstruction with a ready-made type and a custom-made type titanium mesh after mandibular resection in patients with oral cancer. Maxillofac Plast Reconstr Surg 2018;40:35. doi: 10.1186/s40902-018-0175-z.

4. Funayama A, Kojima T, Yoshizawa M, Mikami T, Kanemaru S, Niimi K, Oda Y, Kato Y, Kobayashi T. A simple technique for repositioning of the mandible by a surgical guide prepared using a three-dimensional model after segmental mandibulectomy. Maxillofac Plast Reconstr Surg 2017;39:16. doi: 10.1186/s40902-017-0113-5.

5. Demange MK, Von Keudell A, Probst C, Yoshioka H, Gomoll AH. Patient-specific implants for lateral unicompartmental knee arthroplasty. Int Orthop 2015;39:1519-1526. doi: 10.1007/s00264-015-2678-x.

6. Rotaru H, Schumacher R, Kim SG, Dinu C. Selective laser melted titanium implants: a new technique for the reconstruction of extensive zygomatic complex defects. Maxillofac Plast Reconstr Surg 2015;37:1. doi: 10.1186/\$40902015-0001-9.

7. Rhee SH, Baek SH, Park SH, Kim JC, Jeong CG, Choi JY. 
Total joint reconstruction using computer-assisted surgery with stock prostheses for a patient with bilateral TMJ ankylosis. Maxillofac Plast Reconstr Surg 2019;41:41. doi: 10.1186/s40902-019-0225-1.

8. Takano M, Sugahara K, Koyachi M, Odaka K, Matsunaga S, Homma S, Abe S, Katakura A, Shibahara T. Maxillary reconstruction using tunneling flap technique with 3D custom-made titanium mesh plate and particulate cancellous bone and marrow graft: a case report. Maxillofac Plast Reconstr Surg 2019;41:43. doi: 10.1186/s40902-0190228-y.

9. Woodruff MA, Hutmacher DW. The return of a forgotten polymer- Polycaprolactone in the 21 st century. Prog Polym Sci 2010;35:1217-1256. doi: 10.1016/ j.progpolymsci.2010.04.002.

10. Wang J, Lin C, Gao X, Zheng Z, Lv M, Sun J, Zhang Z. The enhanced osteogenesis and osteointegration of 3-DP PCL scaffolds via structural and functional optimization using collagen networks. RSC Adv 2018;8:32304-32316. doi: 10.1039/C8RA05615C.

11. Ahn G, Lee JS, Yun WS, Shim JH, Lee UL. Cleft alveolus reconstruction using a three-dimensional printed bioresorbable scaffold with human bone marrow cells. J Craniofac Surg 2018;29:1880-1883. doi: 10.1097/ SCS.0000000000004747.

12. Jarcho M. Calcium phosphate ceramics as hard tissue prosthetics. Clin Orthop Relat Res 1981;(157):259-278.

13. Lee S, Choi D, Shim JH, Nam W. Efficacy of threedimensionally printed polycaprolactone/beta tricalcium phosphate scaffold on mandibular reconstruction. Sci Rep 2020;10:4979. doi: 10.1038/s41598-020-61944-w.

14. Shin SH, Kang YJ, Kim SG. The effect of botulinum toxin-A injection into the masseter muscles on prevention of plate fracture and post-operative relapse in patients receiving orthognathic surgery. Maxillofac Plast Reconstr Surg 2018;40:36. doi: 10.1186/s40902-018-0174-0.

15. Park SY, Park YW, Ji YJ, Park SW, Kim SG. Effects of a botulinum toxin type A injection on the masseter muscle: an animal model study. Maxillofac Plast Reconstr Surg 2015;37:10. doi: 10.1186/s40902-015-0010-8.

16. Dwivedi R, Kumar S, Pandey R, Mahajan A, Nandana D, Katti DS, Mehrotra D. Polycaprolactone as biomaterial for bone scaffolds: review of literature. J Oral Biol Craniofac Res 2020;10:381-388. doi: 10.1016/j.jobcr.2019.10.003.

17. Sun H, Mei L, Song C, Cui X, Wang P. The in vivo degradation, absorption and excretion of PCL-based implant. Biomaterials 2006;27:1735-1740. doi: 10.1016/ j.biomaterials.2005.09.019.

18. Chang YL, Stanford CM, Keller JC. Calcium and phosphate supplementation promotes bone cell mineralization: implications for hydroxyapatite (HA)-enhanced bone formation. J Biomed Mater Res 2000;52:270278. doi: 10.1002/1097-4636(200011)52:2<270::aidjbm5>3.0.co;2-1.

19. Park YJ, Cha JH, Bang SI, Kim SY. Clinical application of three-dimensionally printed biomaterial polycaprolactone (PCL) in augmentation rhinoplasty. Aesthetic Plast Surg 2019;43:437-446. doi: 10.1007/s00266-018-1280-1.

20. Kim DH, Yun WS, Shim JH, Park KH, Choi D, Park MI, Hwang SH, Kim SW. Clinical application of 3-dimensional printing technology for patients with nasal septal deformities: a multicenter study. JAMA Otolaryngol Head Neck Surg 2018;144:1145-1152. doi: 10.1001/jamaoto.2018.2054.

21. Kim JH, Lee IG, Lee JS, Oh DY, Jun YJ, Rhie JW, Shim JH, Moon SH. Restoration of the inferomedial orbital strut using a standardized three-dimensional printing implant. J Anat 2020;236:923-930. doi: 10.1111/joa.13136.

22. Han HH, Shim JH, Lee H, Kim BY, Lee JS, Jung JW, Yun WS, Baek CH, Rhie JW, Cho DW. Reconstruction of complex maxillary defects using patient-specific 3D-printed biodegradable scaffolds. Plast Reconstr Surg Glob Open 2018;6:e1975. doi: 10.1097/GOX.0000000000001975.

23. Kim SY. Application of the three-dimensionally printed biodegradable polycaprolactone (PCL) mesh in repair of orbital wall fractures. J Craniomaxillofac Surg 2019;47:10651071. doi: 10.1016/j.jcms.2019.03.009. 